\title{
CJLT

\section{Deriving Empirically-Based Design Guidelines for Advanced Learning Technologies that Foster Disciplinary Comprehension Définir des lignes directrices fondées sur des données empiriques pour les technologies d'apprentissage avancé qui favorisent la compréhension disciplinaire}

\author{
Eric Poitras, McGill University \\ Gregory Trevors, McGill University
}

\begin{abstract}
Planning, conducting, and reporting leading-edge research requires professionals who are capable of highly skilled reading. This study reports the development of an empirically informed computer-based learning environment designed to foster the acquisition of reading comprehension strategies that mediate expertise in the social sciences. Empirical data were gathered in a mixed-methods explanatory sequential design that examined the reading comprehension strategies used by an expert social scientist while reading a professional-level text. Process data were collected through a concurrent think-aloud protocol and coded according to reading comprehension processes. We combined both quantitative and qualitative analyses to identify, describe, and explain patterns in the expert's use of reading strategies. Our findings indicate that highly-skilled reading is characterized by critiquing text information, relating information to prior knowledge, and evaluating one's own understanding of text information. Findings are used to inform the design of worked-examples and a pedagogical agent embedded within the Highly-Skilled Reading Tutor.
\end{abstract}

Keywords: Advanced Learning Technologies, Disciplinary Comprehension

\section{Résumé}

Le type de planification, de réalisation et l'analyse qui caractérise une recherche d'avant-garde nécessite des professionnels en mesure d'effectuer des lectures hautement spécialisées. La présente étude dresse un rapport sur l'élaboration d'un milieu d'apprentissage informatisé conçu pour favoriser l'acquisition de stratégies de compréhension en lecture permettant d'assurer la transmission des connaissances spécialisées en sciences sociales. La collecte de données empiriques s'est effectuée suivant une conception séquentielle explicative fondée sur une 
méthode mixte, qui étudiait les stratégies de compréhension de lecture utilisées par un expert en sciences sociales lors de sa lecture d'un texte de calibre professionnel. La collecte des données sur le processus s'est effectuée suivant un protocole concurrent de réflexion à haute voix, et les données ont été codées conformément aux processus de compréhension de la lecture. Nous avons combiné les analyses quantitatives et qualitatives afin d'identifier, décrire et expliquer les tendances de cet expert dans l'utilisation des stratégies de lecture. Nos résultats indiquent que la lecture hautement spécialisée se caractérise par la critique des informations présentées dans le texte, la mise en relation des informations présentées et des connaissances antérieures et l'autoévaluation de la compréhension de ces informations. Les résultats obtenus sont utilisés pour formuler des exemples façonnés et créer un agent pédagogique intégré au Tuteur de lecture hautement spécialisée.

\section{Introduction}

Advances in research and development depend on the training of professionals and academics that are capable of planning, reporting, and conducting innovative research. As such, postsecondary education plays a crucial role, in light of the current global economic downturn, because it ensures that Canadians have the knowledge and skills that is required to maintain a sustainable economy (Canadian Council on Learning, 2009). However, policy and research organizations in North America, across both public and private sectors, have highlighted a pressing need to improve the graduate training of educational researchers for more than a decade (e.g., Carnegie Foundation, 2003; Institute for Education Sciences, 2004; National Research Council, 2002, 2004).

Amongst the many skills that undergraduate students are expected to acquire during their studies, the ability to analyze, synthesize, and critique scientific articles is especially critical. The existing research shows that expert readers use knowledge from their own disciplines to guide their reading - knowledge of how to create, represent, and evaluate scientific knowledge (Shanahan, 2009; Shanahan \& Shanahan, 2008). In the social sciences and humanities, professional-level scientific articles follow a typical structure, which consists of an introduction, methods, results, and discussion. In these manuscripts, social scientists develop and evaluate research hypotheses and draw conclusions based on their findings. While reading such manuscripts, social scientists use and adjust a wide range of strategies, such as summarizing, elaborating, and seeking clarifications (for a review, see Wyatt et al., 1993) and differ from other academic disciples (Voss, Wiley, \& Carretero, 1995). Their reading is responsive in that it is dependent on their reading goal, prior knowledge, and reactions to the content of the manuscript.

Although important advances have been made in terms of the identification, classification, and description of strategies that mediate expertise in reading scientific articles in the social sciences, little is known in regards to how novices are able to acquire the strategies that are used by experts (Pressley \& Lundeberg, 2008). Since the seminal Wyatt et al. (1993) study first investigated the reading strategies used by social scientists, researchers have yet to translate their findings to guide the design of reading interventions. We believe that the lack of such an educational intervention is critical given that the ability to engage in highly skilled reading is a crucial skill for researchers to advance scientific knowledge in their respective fields. 
In this paper, we begin to address this issue by using advanced learning technologies as a platform to train education researchers that are capable of highly skilled reading. In doing so, this research addresses the following research questions: (1) how can we detect, capture, and represent disciplinary comprehension in the social sciences and humanities? (2) how can we assist students in studying and acquiring examples of disciplinary comprehension with advanced learning technologies?

In order to answer these questions, our research has two objectives: our first objective is to outline a theory-driven approach to capture the reading comprehension strategies that mediates expertise in the social sciences and humanities based on the methodology developed by Wyatt et al. (1993); and our second objective is to use example-based skill acquisition as an instructional framework to derive empirically-based design guidelines in developing a computer-based learning environment called the Highly-Skilled Reading Tutor (Hi-Ski Tutor). The software aims to assist novices to acquire the strategies used by experts while reading professional-level texts in the social sciences and humanities.

\section{Method}

\section{Research Design}

Single-subject mixed methods case studies and experimental research designs enable literacy researchers to translate their findings to practice by exhaustively capturing the complexity of the phenomenon under study in an ecologically valid setting (Neuman \& McCormick, 2002). This research study follows a mixed-methods explanatory sequential design $(N=1)$ in order to investigate the reading comprehension strategies used by a highly skilled social scientist while reading a scientific article. The deployment of macro-level reading comprehension strategies is analyzed quantitatively in terms of frequency across time (i.e., transient analysis of reading strategies based on a 5 minute interval) and probabilities of shifts in strategies (i.e., one- and two-state transitions). Based on the findings of the quantitative analysis, the qualitative analysis aims to describe the micro-level reading comprehension strategies to better capture the reading path at finer levels of granularity.

\section{Participant}

A tenured full social science professor from a research-intensive public Canadian university was selected based on an exemplary level of proficiency in his/her own field of research. Following Wyatt et al. (1993), the identification of a pool of potential expert readers was accomplished according to two criteria: (a) possessing a doctorate in a social or behavioral science, and (b) publishing at least five articles in selective outlets over the last five years. The professor met the aforementioned criteria; furthermore, he/she was recognized internationally for high-ranking scholarly productivity in Contemporary Educational Psychology (Jones et al., 2010) and has extensive editorial experience. The area of specialization of the expert did not focus on reading strategies and skilled reading. The participant was selected using convenience sampling, which involved finding and meeting him/her through the faculty listing posted on the departmental website. 


\section{Material}

The scientific article read by the participant followed a classic or typical social science structure (for review, see Pressley \& Lundeberg, 2008) and was published in a peer-reviewed journal. The article mentioned a title as well as the author(s) and included an abstract, introduction, methods, results, discussion, and references section. First, the abstract summarized the main findings of the study as well as details surrounding the designs and methods that were utilized. The introduction then situated the study within the broader scientific literature regarding the phenomena under investigation. The methods section explained what the participants underwent as part of the experiment. Next, the results section summarized the main findings as well as the statistical analyses that were performed. The discussion section linked these main findings to previous findings obtained in the scientific literature and outlined their significance as well as their limitations. At the end of the article, the references section provided references to all the citations included as part of the article.

\section{Measure}

In order to measure the deployment and fluctuations in the use of reading comprehension strategies while reading professional-level texts, we elicited, recorded, and transcribed concurrent think aloud protocols (Afflerbach \& Pressley, 1995; Ericsson \& Simon, 1980, 1993). Concurrent think aloud protocols involve asking participants to think aloud or verbalize their own thought processes while they are reading the scientific article. The data obtained from these verbal reports can be both analyzed quantitatively by segmenting and categorizing a protocol using a coding scheme and qualitatively by depicting verbal reports in the form of a visual representation (Chi, 1997). The think-aloud procedure is an extensively validated research tool for reading comprehension processes (Afflerbach, 2002; Coté \& Goldman, 1999; Magliano \& Graesser, 1991; Magliano \& Millis, 2003; Magliano, Trabasso, \& Graesser, 1999; Zwaan \& Brown, 1996), and when proper protocol is followed, is non-intrusive on natural cognition (for an extensive review, see Ericsson, 2006; Ericsson \& Simon, 1993).

\section{Procedure}

Following Wyatt et al.'s (1993) study, the participant was informed about the aim of the study (i.e., "To investigate how experts stay current in their fields of expertise"). The participant was asked to select three research articles that were not read beforehand but would be of professional interest to read to stay current within his/her relevant field. The participant was also instructed to not begin reading the article; rather only choose each based on the title and author(s) only. There was no time restriction to find these articles. Upon identifying three articles, the participant informed the researchers which articles he/she had chosen and the experimenter verified to make sure that the articles had an empirical research component and were published in a peer-reviewed scholarly journal. This was indeed the case for all three articles chosen by the professor and two copies of each article were made available for the data collection session.

At the beginning of the experiment, the experimenter asked the participant to choose which one of the three articles he/she wanted to read. The participant was informed that if the article was not interesting, he/she could stop reading and select another one. However, this did not occur during the experiment. The participant was directed to "read the article as you would normally do." In accordance to the guidelines outlined in Ericsson and Simon (1993), the participant was 
instructed to read and to "remember that it is very important to say everything that you are thinking while you are reading the text without explaining or interpreting your thoughts." During reading, the participant's verbal reports were audio-recorded and another experimenter took detailed notes in regards to the participant's non-verbal behaviours (e.g., turning pages, when sections were begun, his/her reactions to the text) in order to facilitate the transcription of the think aloud data. The participant made no markings on the article nor did he/she pause while thinking aloud for more than two minutes. The length of the session was approximately 45 minutes.

\section{Coding and Scoring}

Wyatt and colleagues' (1993) coding scheme was used to analyze the deployment of reading comprehension strategies that are specific to the social sciences while reading professional-level texts (see; Pressley, 2000; Pressley \& Afflerbach, 1995; Pressley \& Lundeberg, 2008; Wyatt et al., 1993). The coding scheme outlined in Wyatt et al. (1993) is based on a grounded (i.e., inductive) approach to studying the cognitive processes used by highly skilled readers in the social sciences. In order to capture all of the processes that occur while reading, the researchers gathered data until no new cognitive processes could be identified (Pressley, 2000; Pressley \& Lundeberg, 2008). Given that the participant in this study is a social sciences professor reading an empirical article, we believe that the codes obtained from this model are both internally and externally valid. The coding scheme includes the following nine categories: goal awareness (GA); awareness (AWA); planful (PLAN); monitoring (MON); relating information to prior knowledge base (RIPK); evaluative reactions (ER); going beyond the information given (elaborations) (ELA); integration (INT); and elucidation of discourse structure (EDS). The following five categories were excluded as part of the current study, due to the fact that they reflect behavioural and affective aspects of reading: linearity and nonlinearity of reading (LNR); written responses (WR); affective reactions (AR); nonverbal responses (NR); and other (OTH).

We also extended certain aspects of this coding scheme on the basis of recommendations outlined by Azevedo and Witherspoon (2009) in terms of the operationalization of constructs by taking into account their granularity and valence. We also specified the valence of specific constructs (positive and negative) as well as identifying utterances where the participant was simply reading the contents of the article (coded as 'READ'). The resulting coding scheme shows definitions and examples in relation to each construct.

The data consisted of 39 minutes of audio recording of the participant's concurrent think aloud while reading the article. The transcription yielded a corpus of 5,974 words. Segmentation was done based on the semantic features of an utterance as a means to determine segment boundaries (see Chi, 1997). In total, the segmentation yielded 90 instances of reading, 94 utterances and wherein 167 segments were identified, each of which were assigned a code from the formalism shown in Appendix A.

\section{Coding Reliability}

To establish reliability of the think-aloud coding scheme, a randomly selected sample consisting of $20 \%$ of the total utterances was coded independently by two raters. Cohen's kappa was calculated on this sample to assess inter-rater agreement, and was determined to be good (к $=$ $.68, S E=.08)$. Disagreements were resolved through discussion. Following this, the remaining 
utterances were divided between the two raters to code independently (i.e., $40 \%$ of the total amount of utterances each). Frequencies of each code for all utterances were then tallied.

\section{Results}

\section{Transient Analysis of Reading Comprehension Strategies}

In order to examine the temporal deployment of macro-level reading comprehension strategies, Table 1 shows the total frequencies of strategies used by the expert (i.e., rows) over eight 5minute segments of time (i.e., columns) that make up the total amount of time spent reading the text (i.e., 39min:14 sec). Given that the expert read the article from beginning to end, the position of each 5-minute segment roughly corresponds to the linear position in the text (e.g., the eighth and last segment represents the end of the journal article). The most frequently used strategy by the expert was simply reading a segment of text, which was found to be used more frequently all throughout reading except during the last 5-minute segment ${ }^{1}$ (i.e., overall, reading accounted for 90 occurrences out of a total of 257). During the last 5-minute segment, the expert engaged more frequently in evaluative reactions. Content evaluation was also the second most frequently used strategy overall (49 occurrences out of a total of 257) and was most predominantly employed during the second, third, seventh and eighth 5-minute segment. Monitoring and relating information to prior knowledge seemed to co-occur especially during the first, second, fifth and seventh 5-minute segment (i.e., 27 and 32 out of a total of 257, respectively). Elaborations, affective reactions, and planful were used less frequently $(15,15$, and 10 out of a total of 257 , respectively) while integration, awareness, goal awareness, elucidation of discourse structure and other strategies were rarely used (less than 5 out of a total of 257). Therefore, the nature of highly-skilled reading comprehension is characterized by evaluating aspects of the text and its relevance to the reading goal, evaluating one's own understanding of the text, as well as activating prior knowledge in order to make sense of the text.

\section{State-Transitions in Reading Comprehension Strategies}

Likelihood metrics have been used in previous research to capture the temporal deployment of learning strategies during learning (see Azevedo, Moos, Johnson, \& Chauncey, 2010; D’Mello, Olney, \& Person, 2010; D'Mello, Taylor, \& Graesser, 2007; Witherspoon, Azevedo, \& D'Mello, 2008). This form of state-transition analysis is performed by creating a matrix of all the possible learning strategies in order to calculate the probability estimate of transitioning from one state to another.

In order to derive a likelihood metric that appropriately captures the temporal deployment of reading comprehension strategies, we opted to distinguish between the frequency and probability of shifting from one strategy to another (e.g., frequency and probability of generating an evaluating reaction following reading a segment of text). Frequencies in shifting literacy strategies was calculated by counting the number of times a literacy strategy "X" at Time $i$ lead to another strategy "Y" at Time $i+1$. Probabilities in shifting literacy strategies were calculated by dividing the frequencies by the total number of time shifts in strategies originated from literacy strategy " $\mathrm{X}$ ". In doing so, we were able to calculate the percentage of variability in

\footnotetext{
${ }^{1}$ The last interval corresponds to 4 minutes and 14 seconds as opposed to the other 5 minutes interval used for the rest of the table. Judging by the length and frequency of reading comprehension strategy used during the last phase of reading, we judged that this gap would have little impact on our findings.
} 
strategy use that is accounted for by a particular type of shift (see Figure 1). Therefore, frequencies reflect the overall importance rather than probability.

Table 1. Total raw frequency of reading comprehension strategies characterizing highly skilled reading used over time

\begin{tabular}{|l|c|c|c|c|c|c|c|c|c|}
\hline \multirow{2}{*}{ Comprehension Process } & \multicolumn{7}{|c|}{ Time } \\
\cline { 2 - 11 } & T1 & T2 & T3 & T4 & T5 & T6 & T7 & T8 & Overall \\
\hline Reading & 13 & 13 & 12 & 11 & 8 & 10 & 17 & 6 & 90 \\
\hline Elucidation of discourse structure & 0 & 0 & 0 & 0 & 0 & 1 & 0 & 0 & 1 \\
\hline Integration & 0 & 1 & 2 & 1 & 0 & 0 & 1 & 0 & 5 \\
\hline Awareness & 0 & 1 & 0 & 0 & 0 & 3 & 1 & 0 & 5 \\
\hline Elaborations & 1 & 3 & 2 & 2 & 2 & 1 & 0 & 4 & 15 \\
\hline Affective reactions & 0 & 3 & 1 & 0 & 3 & 2 & 4 & 2 & 15 \\
\hline Planful & 1 & 3 & 1 & 2 & 3 & 0 & 0 & 0 & 10 \\
\hline Monitoring & 4 & 6 & 3 & 3 & 5 & 2 & 4 & 0 & 27 \\
\hline Evaluative reactions & 53 & 47 & 31 & 25 & 29 & 27 & 43 & 22 & 257 \\
\hline Relating information to prior \\
knowledge
\end{tabular}

Note. Times are reported in five minute intervals with last interval stopping at $39 \mathrm{~min}$ and $14 \mathrm{sec}$; Linearity and Nonlinearity or Reading (LNR) excluded from the analysis. 


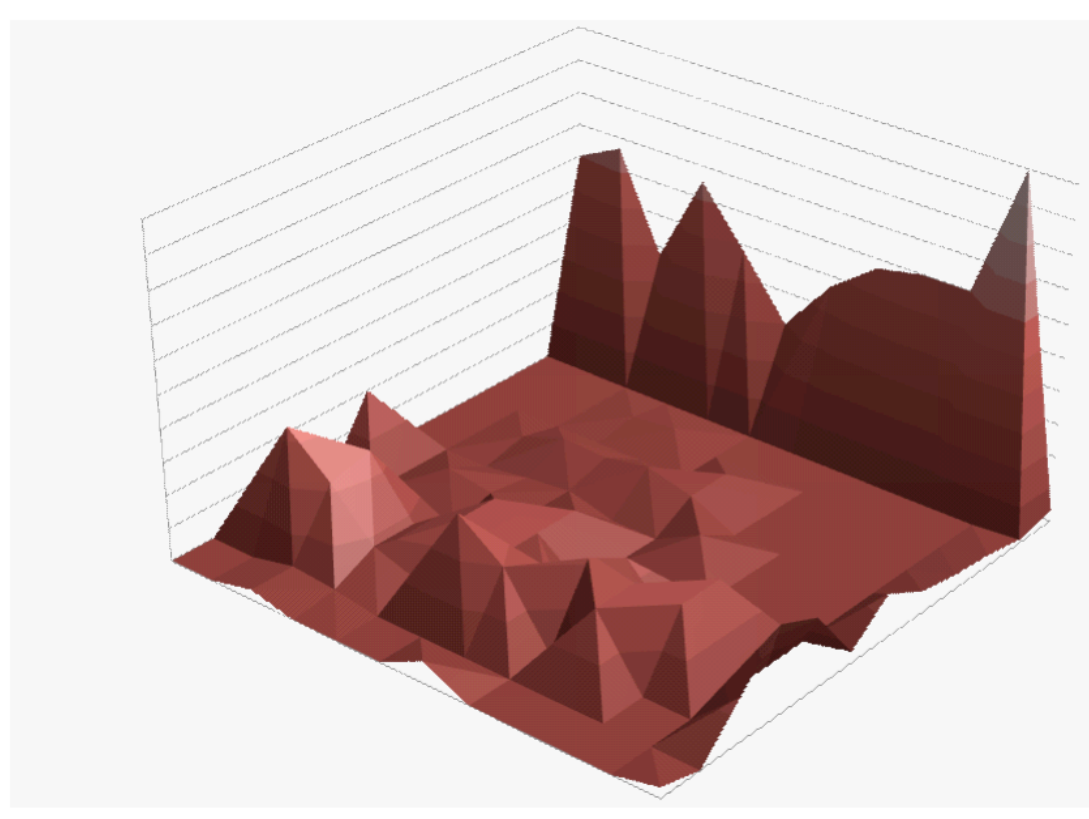

\section{Figure 1. Reading comprehension strategies state-transition matrix: Computing probabilities in single shifts in strategies}

\section{Single-State Transitions.}

In regards to the transitions involving reading, the results of the single-state transition analysis show that highly skilled reading is characterized by shifting from reading to evaluating aspects of the text ( 24 occurrences accounting for a third of all strategies used after reading). In addition to evaluative reactions, which were found to lead more often to reading, engaging in monitoring or evaluating one's own understanding followed reading segments of the text more often, which suggests that it might be closely tied to aspects of the text (19 occurrences accounting for a fifth of all strategies used after reading). Relating information to prior knowledge occurred equally often before and after reading (12 occurrences accounting for a tenth of all strategies used after reading).

In regards to the transitions involving strategies, the results of the single-state transition analysis show that there is a great amount of variability in the strategies used following evaluative reactions, since elaborations occurred most frequently but still only accounted for a small percentage of variance ( 4 occurrences accounting for $8 \%$ of all strategies used after evaluative reactions). The transitions originating from monitoring, however, were more homogeneous with evaluating one's own understanding of the text and critiquing aspects of the study occurring most often (each of them occurring on 4 occasions and accounting for $15 \%$ of all strategies used after monitoring). Finally, relating information to prior knowledge was found to be frequently followed by evaluating aspects of the study ( 8 occurrences accounting for $25 \%$ of all strategies used after relating information to prior knowledge). 
Table 2. Frequencies and probabilities in one shift in reading comprehension strategies characterizing highly skilled reading

\begin{tabular}{|l|c|}
\hline \multicolumn{1}{|c|}{ Comprehension Process } & $\begin{array}{c}\text { Frequency } \\
\text { (Probability) }\end{array}$ \\
\hline Evaluative Reactions $\rightarrow$ Reading & $32(65 \%)$ \\
\hline Reading $\rightarrow$ Evaluative Reactions & $24(27 \%)$ \\
\hline Reading $\rightarrow$ Monitoring & $19(21 \%)$ \\
\hline Monitoring $\rightarrow$ Reading & $13(48 \%)$ \\
\hline Relating Information To Prior Knowledge $\rightarrow$ Reading & $12(38 \%)$ \\
\hline Reading $\rightarrow$ Relating Information To Prior Knowledge & $12(13 \%)$ \\
\hline Reading $\rightarrow$ Affective Reaction & $12(13 \%)$ \\
\hline Relating Information To Prior Knowledge $\rightarrow$ Evaluative Reactions & $8(25 \%)$ \\
\hline Elaboration $\rightarrow$ Reading & $8(57 \%)$ \\
\hline Relating Information To Prior Knowledge $\rightarrow$ Relating Information To & $7(22 \%)$ \\
\hline Prior Knowledge & $7(47 \%)$ \\
\hline Affective Reaction $\rightarrow$ Reading & $6(7 \%)$ \\
\hline Reading $\rightarrow$ Elaboration & $4(4 \%)$ \\
\hline Reading $\rightarrow$ Awareness & $4(8 \%)$ \\
\hline Evaluative Reactions $\rightarrow$ Elaboration & $4(15 \%)$ \\
\hline Monitoring $\rightarrow$ Monitoring & $4(15 \%)$ \\
\hline Monitoring $\rightarrow$ Evaluative Reactions & $4(8 \%)$ \\
\hline Evaluative Reactions $\rightarrow$ Relating Information To Prior Knowledge & $4(8 \%)$ \\
\hline Evaluative Reactions $\rightarrow$ Evaluative Reactions & Ro \\
\hline
\end{tabular}

Note. Top 10\% ranked frequencies (18 of 144 shifts); Frequency $=$ Count of shifts from Process $x$ at Time i to Process $y$ at Time $i+1$; Probability $=$ Count of shifts from Process $x$ at Time $i$ to variable $y$ at Time $i+1$ divided by the total count of shifts related to Process $x^{(2)}$. Linearity and Nonlinearity of Reading excluded from the analysis.

2 The data provided in the table consists of only a sample of all the data included in the analysis. This sample corresponds to 18 out of 144 data shifts. The sample was selected on the basis that the highest frequencies are shown. These frequencies correspond to the count of shifts from state " $\mathrm{X}$ " to " $Y$ ". For example, the expert shifted from reading to elaborating on 6 occasions. The probabilities consist of the frequencies divided by the sum of shifts from "X" (i.e., to $Y 1, Y 2, \ldots$ Yn). For example, the shift from Reading to Elaborating corresponds to $7 \%$ of all shifts from Reading. 
Table 3. Frequencies and probabilities in two shifts in reading comprehension strategies characterizing highly skilled reading

\begin{tabular}{|l|c|}
\hline \multicolumn{1}{|c|}{ Comprehension Process } & $\begin{array}{c}\text { Frequency } \\
\text { (Probability) }\end{array}$ \\
\hline Reading $\rightarrow$ Evaluative Reactions $\rightarrow$ Reading & $15(17 \%)$ \\
\hline Reading $\rightarrow$ Monitoring $\rightarrow$ Reading & $11(12 \%)$ \\
\hline Evaluative Reactions $\rightarrow$ Reading $\rightarrow$ Evaluative Reactions & $11(23 \%)$ \\
\hline Evaluative Reactions $\rightarrow$ Reading $\rightarrow$ Monitoring & $8(17 \%)$ \\
\hline $\begin{array}{l}\text { Relating Information To Prior Knowledge } \rightarrow \text { Evaluative Reactions } \rightarrow \\
\text { Reading }\end{array}$ & $7(22 \%)$ \\
\hline Reading $\rightarrow$ Relating Information To Prior Knowledge $\rightarrow$ Reading & $6(7 \%)$ \\
\hline Reading $\rightarrow$ Affective Reactions $\rightarrow$ Reading & $6(7 \%)$ \\
\hline $\begin{array}{l}\text { Evaluative Reactions } \rightarrow \text { Reading } \rightarrow \text { Relating Information To Prior } \\
\text { Knowledge }\end{array}$ & $5(10 \%)$ \\
\hline Reading $\rightarrow$ Elaborations $\rightarrow$ Reading & $4(4 \%)$ \\
\hline Evaluative Reactions $\rightarrow$ Reading $\rightarrow$ Affective Reactions & $4(8 \%)$ \\
\hline $\begin{array}{l}\text { Elaboration } \rightarrow \text { Reading } \rightarrow \text { Evaluative Reactions } \\
\text { Relating Information To Prior Knowledge } \rightarrow \text { Relating Information To Prior }\end{array}$ & $4(29 \%)$ \\
\hline Knowledge $\rightarrow$ Evaluative Reactions & $4(13 \%)$ \\
\hline $\begin{array}{l}\text { Evaluative Reactions } \rightarrow \text { Relating Information To Prior Knowledge } \rightarrow \\
\text { Relating Information To Prior Knowledge }\end{array}$ & $3(6 \%)$ \\
\hline $\begin{array}{l}\text { Reading } \rightarrow \text { Relating Information To Prior Knowledge } \rightarrow \text { Relating } \\
\text { Information To Prior Knowledge }\end{array}$ & $3(3 \%)$ \\
\hline $\begin{array}{l}\text { Reading } \rightarrow \text { Affective Reactions } \rightarrow \text { Relating Information To Prior } \\
\text { Knowledge }\end{array}$ & $3(3 \%)$ \\
\hline $\begin{array}{l}\text { Relating Information To Prior Knowledge } \rightarrow \text { Reading } \rightarrow \text { Relating } \\
\text { Information To Prior Knowledge }\end{array}$ & $3(9 \%)$ \\
\hline Affective Reactions $\rightarrow$ Reading $\rightarrow$ Evaluative Reactions & $3(20 \%)$ \\
\hline Reading $\rightarrow$ Monitoring $\rightarrow$ Monitoring & $3(3 \%)$ \\
\hline Monitoring $\rightarrow$ Reading $\rightarrow$ Monitoring & $3(11 \%)$ \\
\hline Reading $\rightarrow$ Other $\rightarrow$ Reading & $3(21 \%)$ \\
\hline Elaboration $\rightarrow$ Evaluative Reactions $\rightarrow$ Reading & $3(11 \%)$ \\
\hline Monitoring $\rightarrow$ Evaluative Reactions $\rightarrow$ Reading & \\
\hline & \\
\hline
\end{tabular}


Note. Top 1\% ranked frequencies (22 of 1728 shifts); Frequency $=$ Count of shifts from Process $x$ at Time $i$ to Process $y$ at Time $i+1$ to Process $z$ at Time $i+2$; Probability $=$ Count of shifts from Process $x$ at Time $i$ to Process $y$ at Time $i+1$ and Process $z$ at Time $i+2$ divided by the total count of shifts in regards to Process $x$. Linearity and Nonlinearity of Reading excluded from the analysis.

\section{Two-State Transitions.}

The examination of the two-state transition analysis triggered by reading a segment of text corroborates the findings obtained in the analysis focusing on a single shift. In descending order, there is a high likelihood of shifting from reading to: evaluative reactions (i.e., ranked 1st overall with 15 occurrences), monitoring (i.e., ranked 2 nd overall with 11 occurrences), and relating information to prior knowledge (i.e., ranked 6th overall with 6 occurrences); and then shifting back to reading (i.e., accounting for $17 \%, 12 \%$, and $7 \%$ of all two-state transitions triggered by reading, respectively).

Furthermore, the two-state transition analysis triggered by the use of strategies shows evidence in favour of the critical role of reacting through evaluating aspects of the study in highly-skilled reading. There was a high likelihood of using either evaluative reactions (ranked 3rd overall; 11 occurrences accounting for $23 \%$ of all two-state transitions triggered by evaluative reactions) or monitoring (ranked 4th overall; 8 occurrences accounting for $17 \%$ of all two-state transitions triggered by evaluative reactions) following reading segments of text triggered by evaluating aspects of the text. Finally, using prior knowledge was also instrumental in evaluating aspects of the text followed by reading (ranked 5th overall; 7 occurrences accounting for $22 \%$ of all twostate transitions triggered by using prior knowledge).

\section{Qualitatively Depicting the Reading Comprehension Strategies that Mediate Expertise}

In order to provide converging evidence for the state-transition analysis and further describe the characteristics of highly skilled reading, we validated this quantitative analysis by substantiating it with a two-pass approach to coding the qualitative data (Chi, 1997). First, we identified the expert's reading goal, which was to "I want to find out what this group is doing in particular [...] and one of the reasons for reading this, I want to know what they are doing especially since we are getting into eye tracking and we're using that in our lab." Second, the protocol was searched for occurrences of the desired state transition of literacy strategies (i.e., Reading $\rightarrow$ Evaluative Reactions $\rightarrow$ Reading) as a means to describe their properties at a finer grain level as well as their valence and aspects related to their content.

Table 4 shows that the micro-level processes of Evaluative Reactions to the text. More specifically, reactions were focused on aspects of the research methodology that was reported, the writing and editing of the paper, the analyses, conclusions, and the citations used. Only one of the eight evaluative reactions had a positive valence meaning that the expert judged this aspect of the analysis as being a strength (e.g., "Oh that's good, ok"). The others had a negative valence meaning that the expert had identified a limitation in regards to a certain aspect of the study, which was judged to be problematic (e.g., "This doesn't sound like a very well controlled experiment"). 
CJLT/RCAT Vol. 38(1)

Table 4. Qualitative data coded during the second-pass for Evaluative Reactions

\begin{tabular}{|c|c|c|c|c|}
\hline & & \multicolumn{3}{|c|}{ Sequence of Literacy Strategies } \\
\hline Valence & Focus & 1st - Reading & $\begin{array}{c}\text { 2nd - Evaluative } \\
\text { Reactions }\end{array}$ & 3rd - Reading \\
\hline $1 \quad(-)$ & $\begin{array}{c}\text { Writing/ } \\
\text { editing style }\end{array}$ & $\begin{array}{l}\text { Tasks with a complex, } \\
\text { dynamic visual component } \\
\text { require not only the } \\
\text { acquisition of conceptual/ } \\
\text { procedural but also of } \\
\text { perceptual/attentional } \\
\text { skills. }\end{array}$ & $\begin{array}{l}\text { I'm wondering why they } \\
\text { put conceptual and } \\
\text { procedural with a slash. } \\
\text { They're not used } \\
\text { interchangeably but ... }\end{array}$ & $\begin{array}{l}\text { This study examined } \\
\text { expertise differences in } \\
\text { perceiving and interpreting } \\
\text { complex, dynamic visual } \\
\text { stimuli on a performance } \\
\text { and on a process level, } \\
\text { including perceptual and } \\
\text { conceptual strategies. }\end{array}$ \\
\hline $2 \quad(-)$ & Methods & $\begin{array}{l}\text { Performance, eye } \\
\text { movement, and verbal } \\
\text { report data were obtained } \\
\text { from seven experts and } 14 \\
\text { novices. }\end{array}$ & $\begin{array}{l}\text { Ok, so I see that we're } \\
\text { heading towards a problem } \\
\text { with unequal sample size } \\
\text { um... }\end{array}$ & $\begin{array}{l}\text { Results show that experts } \\
\text { compared to novices attend } \\
\text { more to relevant aspects of } \\
\text { the stimuli. }\end{array}$ \\
\hline $3 \quad(-)$ & \begin{tabular}{|c|} 
Writing/ \\
editing style
\end{tabular} & $\begin{array}{l}\text { In many domains, expert } \\
\text { performance also comprises } \\
\text { perceptual/attentional } \\
\text { skills, that is, the ability to } \\
\text { perceive the relevant out of } \\
\text { irrelevant information. }\end{array}$ & $\begin{array}{l}\mathrm{Hm} \text {... well, ok, } \\
\text { information is used in a } \\
\text { weird sense there, euuh... }\end{array}$ & $\begin{array}{l}{[\ldots] \text { highly visual stimuli }} \\
\text { and to draw inferences } \\
\text { based upon the perceived } \\
\text { information. }\end{array}$ \\
\hline $4 \quad(-)$ & Methods & $\begin{array}{l}\text { This was done in order to } \\
\text { avoid an artificial situation } \\
\text { for both groups. On the one } \\
\text { hand, novices might not be } \\
\text { able to describe the } \\
\text { locomotion pattern after all } \\
\text { after a too short } \\
\text { presentation. On the other } \\
\text { hand, experts were forced } \\
\text { to look at a stimulus that } \\
\text { they had interpreted } \\
\text { already. }\end{array}$ & $\begin{array}{l}\text { Geez this doesn't sound } \\
\text { like a very well controlled } \\
\text { experiment anyways, ok. }\end{array}$ & $\begin{array}{l}\text { Eye tracking Tobii } 1750 \text { ok } \\
50 \mathrm{~Hz} \text { ClearView software } \\
\text { the verbal data were } \\
\text { recorded by Camtasia }\end{array}$ \\
\hline $5 \quad(-)$ & Method & $\begin{array}{l}\text { At the beginning, the eye } \\
\text { tracking system was } \\
\text { adjusted to the individual } \\
\text { features. Before watching } \\
\text { the videos while watching } \\
\text { the video, please take a } \\
\text { look at the way the fish } \\
\text { swims. Subsequent to } \\
\text { watching the video, you } \\
\text { will have to describe the } \\
\text { fish's locomotion pattern. } \\
\text { You will also be allowed to } \\
\text { watch the video as often as } \\
\text { you like. }\end{array}$ & $\begin{array}{l}\text { Ok so there is- there's no- } \\
\text { there is a goal but there is } \\
\text { no explicit goal, so in terms } \\
\text { of methodology I'm } \\
\text { wondering, I mean, well } \\
\text { you know euh it could be } \\
\text { more precise but that's just } \\
\text { being critical of the } \\
\text { method. }\end{array}$ & $\begin{array}{l}\text { Then, participants watched } \\
\text { the looped video while their } \\
\text { eye movements were } \\
\text { recorded until they stopped } \\
\text { it themselves. After having } \\
\text { watched the video, } \\
\text { participants were asked to } \\
\text { describe the locomotion } \\
\text { pattern of the depicted fish } \\
\text { verbally[...] }\end{array}$ \\
\hline
\end{tabular}




\begin{tabular}{|c|c|c|c|c|}
\hline $6 \quad(+)$ & Analyses & $\begin{array}{l}\text { We refer to these } \\
\text { aggregated AOIs as } \\
\text { AAOIs. }\end{array}$ & Oh that's good, ok. & $\begin{array}{l}\text { The first dependent variable } \\
\text { was the mean viewing } \\
\text { duration per video. }\end{array}$ \\
\hline $7 \quad(-)$ & Conclusions & $\begin{array}{l}\text { In addition, findings } \\
\text { obtained from this study } \\
\text { were intended to inform the } \\
\text { instructional design of } \\
\text { process- ok ah - hypothesis } \\
1 \text { experts would perform } \\
\text { more accurately and faster } \\
\text { than novices on a } \\
\text { locomotion description task } \\
\text { - the respective test, } \\
\text { however, mostly served as } \\
\text { a manipulation check. }\end{array}$ & $\begin{array}{l}\text { Wow yeah, I mean that } \\
\text { hypothesis is you didn't } \\
\text { have to do this study to do } \\
\text { that but let's move right } \\
\text { along. }\end{array}$ & $\begin{array}{l}\text { More important, based on } \\
\text { prior findings with static } \\
\text { complex visual stimuli. }\end{array}$ \\
\hline $8 \quad(-)$ & Citations & $\begin{array}{l}\text { More important, based on } \\
\text { prior findings with static } \\
\text { complex visual stimuli. }\end{array}$ & $\begin{array}{l}\text { Ok why is this stuff so old? } \\
\text { Why are they citing old } \\
\text { research? }\end{array}$ & $\begin{array}{l}{[\ldots] \text { hypothesized that also }} \\
\text { in this dynamic domain the } \\
\text { process data of experts } \\
\text { would show that they } \\
\text { attend more to relevant } \\
\text { information than novices, } \\
\text { who would rather attend to } \\
\text { perceptually salient, but } \\
\text { potentially conceptually } \\
\text { irrelevant. }\end{array}$ \\
\hline
\end{tabular}

Therefore, reacting to aspects of the study after and before reading was characterized as a highly critical form of strategy. As such, the second-pass through the concurrent think aloud protocol enables us to validate our initial analysis that informed the creation of visual depictions of highly skilled reading. In order to foster expertise, we created visual representations of the reading comprehension strategies that mediate highly skilled reading as a means to provide students with double-content examples to facilitate skill acquisition. Each segments of the concurrent think aloud protocol can be shown as boxes showing the contents of the highly skilled reader's utterances (see Figure 2). Each box is interrelated according to the order in which its content was uttered. Moreover, it is indexed in regards to whether the expert was reading or verbalizing the use of a particular strategy and its location in relation to the text. As such, these visual depictions can represent the state transitions in the use of reading comprehension strategies as a means to foster expertise in reading professional-level texts. These visual depictions of highly skilled reading can also be embedded in the context of a computer-based learning environment (Figure 3). In doing so, learners can be assisted through technology-based scaffolding mechanisms in studying examples of the key reading comprehension strategies that were found to mediate highly-skilled reading. 


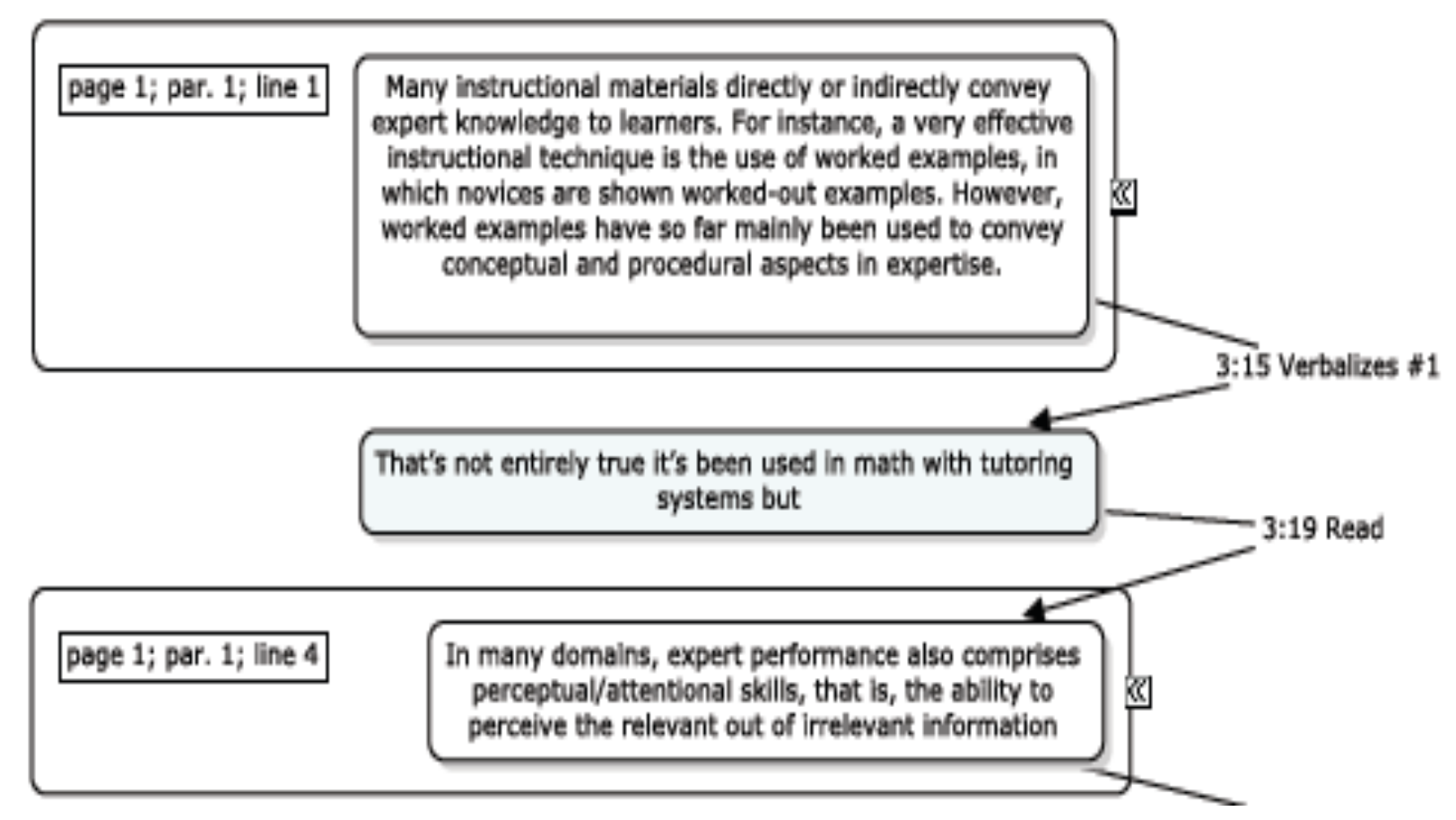

Figure 2. Visually depicting shifts in reading comprehension strategies that mediate highlyskilled reading

\section{Discussion and System Development}

The objective of this study was to examine highly skilled reading in the social sciences as a means to derive theoretically-based and empirically-based design guidelines for advanced learning technologies. Specifically, we expected that the literacy strategies used by social scientists reading while reading professional-level texts could be visually represented as workedexamples of heuristic solution strategies. Our findings indicate that highly-skilled reading in the social sciences is characterized by critiquing text information, relating information to prior knowledge, and evaluating one's own understanding of text information. In the following sections, we review the theoretical and empirical literature on example-based skill acquisition. We then discuss the implications for the design of the Highly-Skilled Reading Tutor, a singleagent intelligent system that assists students in studying double-content examples of the reading comprehension strategies that are the most characteristic of highly-skilled reading in the social sciences.

\section{Using Example-Based Skill Acquisition as an Instructional Model}

In order to support undergraduate students in learning about the reading comprehension strategies that mediate expertise in the social sciences, we use example-based skill acquisition as an instructional model (see Atkinson, Derry, Renkl, \& Wortham, 2000; Renkl, 2005, 2010; Renkl \& Atkinson, 2003, 2007, 2010). The main assumption of the instructional model states that the combination of worked examples with principle-based self-explanation prompts facilitates skill acquisition. Based on cognitive load theory (Chandler \& Sweller, 1991; Sweller, 1994; Sweller, Van Merrienboer, \& Paas, 1998), the worked examples are expected to increase the amount of cognitive resources available in working memory. In contrast to the worked 
examples, principle-based self-explanation prompts ensure that additional cognitive resources are directed towards reflecting on the rationale that underlies the skill illustrated by the example.

Renkl, Hilbert, and Schworm (2009), and van Gog and Rummel (2010) have recently begun to use worked examples to demonstrate different types of heuristic strategies such as deriving mathematical proofs and formulating arguments. Reading professional-level texts in the social sciences consists of an ill-structured task, since it involves the acquisition of complex knowledge through the application of domain-specific concepts and skills. Examples of the skills used in this domain distinguish between two types of elements: The first, which is the learning domain, consists of the problem-solving structure (e.g., the strategy used to read the text, such as critiquing an aspect of the methodology); while the second, which is the exemplifying domain, refers to the problem-solving topic (e.g., the topic of the text being read, such as reading about the methodology used in the study).

Skill acquisition can also be facilitated by providing novices with principle-based selfexplanation prompts while they are studying the examples (Schworm \& Renk1, 2006, 2007; Rummel et al., 2006). Principle-based self-explanation prompts assist students in generating explanations in relation to the use of heuristic strategies, thereby relating the novices' prior knowledge to the learning domain that is depicted in the worked example. For instance, selfexplanation prompts that focus on the learning domain can prompt students by asking them "Which reading strategy does this example illustrate?" as well as "How is it related to the reading goal?"

Salden, Koedinger, Renkl, Aleven, and McLaren (2010) used computer-based learning environments as a means to implement and evaluate the effectiveness of interventions while investigating the impact of example-based skill acquisition on skill acquisition. The existing empirical research that example-based skill acquisition is an efficient and effective means to facilitate the acquisition of skills involved in well-structured domains such as geometry and chemistry (McLaren, Lim, \& Koedinger, 2008; Salden, Koedinger, Renk1, Aleven, \& McLaren, 2010; Schwonke et al., 2009). Indeed, computer-based learning environments offer numerous advantages, such as controlling the sequence of examples based on students' performance in generating self-explanations as well as providing corrective feedback.

However, the effects of example-based skill acquisition in the social sciences, as opposed to other ill-structured domains, have yet to be investigated (Hilbert, Renkl, Schworm, Kessler, \& Reiss, 2008; Hilbert, Renkl, Kessler, \& Reiss, 2008; Schworm \& Renkl, 2006). Therefore, the design of computer-based learning environments based on example-based skill acquisition as an instructional model has a significant potential to facilitate the acquisition of the reading comprehension strategies that mediate expertise in the social sciences, thereby contributing to both scientific knowledge and practice.

\section{The Highly-Skilled Reading Tutor}

The Highly-Skilled Reading Tutor is a computer-based learning environment that is designed to facilitate the acquisition of the reading comprehension strategies that mediate expertise in the social sciences. The elements of design for the Highly-Skilled Reading Tutor include the pedagogical agent module, the text module, and the example module. 


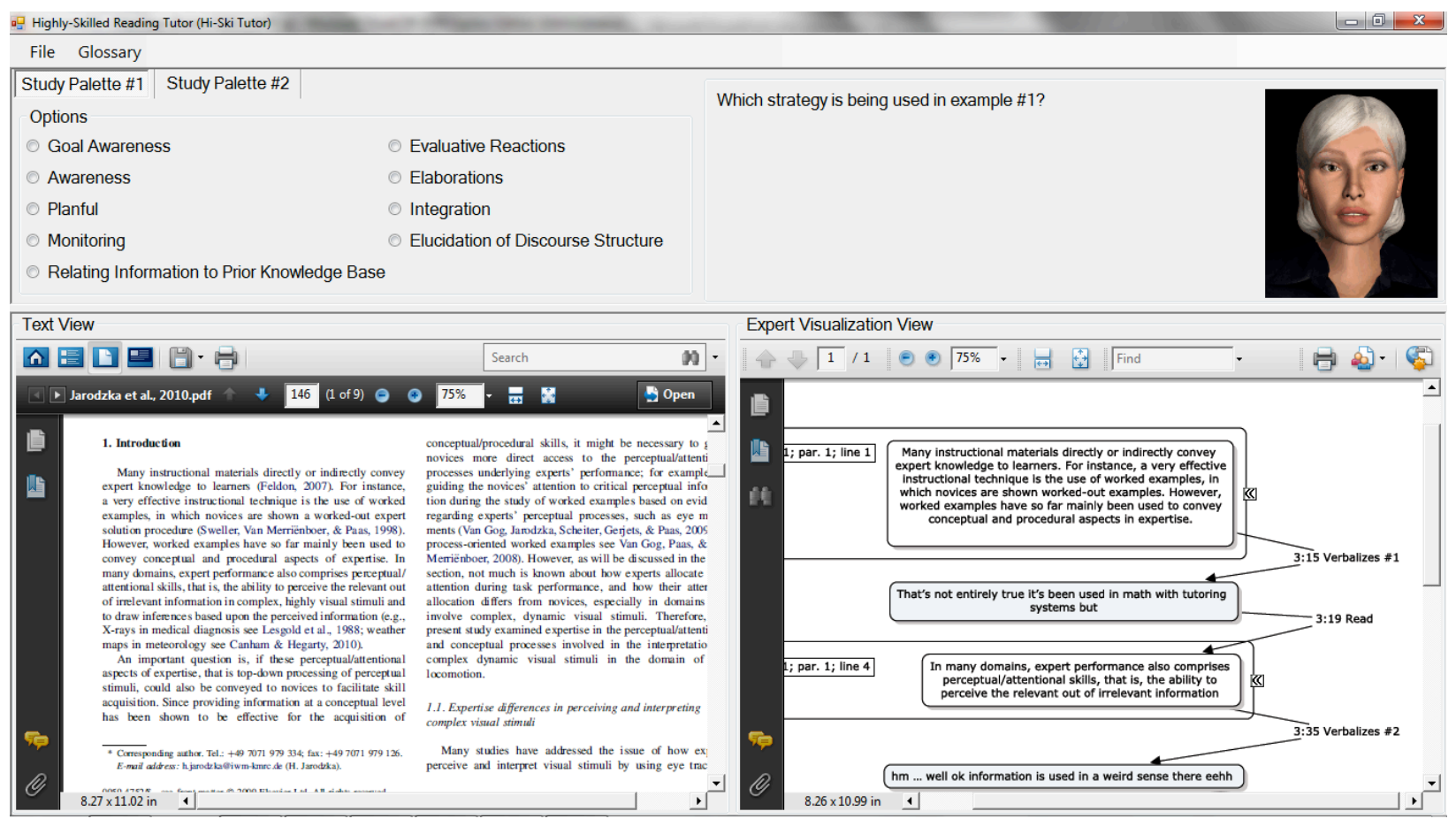

Figure 3. Screen capture of the Highly-Skilled Reading Tutor

The pedagogical agent, also called artificial agent, can interact with students to facilitate knowledge construction through the use of verbal communication (Graesser, Jeon, \& Dufty, 2008). Pedagogical agents can simulate social interaction through different modalities such as speech, facial expression, eye movement, gesture, and posture (Dehn \& Mulken, 2000; Johnson, Rickel, \& Lester, 2000; Kim \& Baylor, 2006). In a review of the literature, Graesser, D’Mello, and Person (2009) indicated that pedagogical agents can parallel and extend the adaptiveness and effectiveness of one-on-one tutoring by demonstrating the appropriate use of learning strategies.

The text module enables students to load any social science manuscript in an Adobe Acrobat Reader embedded as part of the environment. Students are thus able to read the text while having the benefit of the features of this software, which include the ability to focus or zoom-in or -out, review the structure of the paper, and view annotated comments.

The example module provides students with double-content examples of reading comprehension strategies (i.e., visual representation of highly-skilled reading in the social sciences, also saved in a .pdf format and shown in an Adobe Acrobat Reader interface). The example includes reference to the part of the text the expert was reading in order to enable students to examine the reading path of the expert.

Based on example-based skill acquisition as an instructional model (Renkl, Hilbert, \& Schworm, 2009; van Gog \& Rummel, 2010) and cognitive load theory (Chandler \& Sweller, 1991; Sweller, 1994; Sweller, Van Merrienboer, \& Paas, 1998), the instructional principles that guide the pedagogical agent aim to assist students in studying worked-examples of highly skilled reading. The Highly-Skilled Reading Tutor directs learners' cognitive resources to activities that are relevant to learning (i.e., maximizing germane load through principle-based self-explanation prompts provided by the pedagogical agent) rather than to processing irrelevant information (i.e., reduce extraneous load through studying worked out examples of highly skilled reading). By 
analogy to the recent advances in tutored problem-solving with intelligent systems in wellstructured and algorithmic domains (see McLaren et al., 2008; Salden et al., 2010; Schwonke et al., 2009), the principle-based self-explanation prompts are combined with corrective feedback and a glossary as a means to focus learners' attention on the learning-domain or literacy strategies, thereby avoiding to induce extraneous cognitive load. Furthermore, the worked examples of highly skilled reading are adaptively faded based on the learners' correctness of responses generated to the principle-based self-explanation prompts.

The Highly-Skilled Reading Tutor stands to better prepare social scientists who are capable of highly-skilled reading, a skill which is critical in planning, conducting, and reporting leadingedge research. Future research will examine the nature of highly-skilled reading in the social sciences by manipulating aspects in relation to the text and reader as a means to (1) further develop the worked examples embedded in the Highly-Skilled Reading Tutor and (2) implement and evaluate the effectiveness of the Highly-Skilled Reading Tutor in terms of enhancing learning.

\section{Acknowledgements}

We would like to acknowledge the funding received by the Social Sciences and Humanities Research Council of Canada.

\section{References}

Afflerbach, P. (2002). Verbal reports and protocol analysis. In M. L. Kamil, P. B. Mosenthal, P. D. Pearson, \& R. Barr (Eds.), Handbook of reading research (Vol. III, pp. 87-103). Mahwah, NJ: LEA.

Atkinson, R. K., Derry, S. J., Renk1, A., \& Wortham, D. (2000). Learning from examples: Instructional principles from the worked examples. Review of Educational Research, 70(2), 181-214.

Azevedo, R., \& Witherspoon, A. M. (2009). Self-regulated learning with hypermedia. In D. J. Hacker, J. Dunlosky, \& A. C. Graesser (Eds.), Handbook of metacognition in education (pp. 319-339). Mahwah, NJ: Routledge.

Azevedo, R., Moos, D. C., Johnson, A. M., \& Chauncey, A. (2010). Measuring cognitive and metacognitive regulatory processes during hypermedia learning: Issues and challenges. Educational Psychologist, 45(4), 210-223.

Canadian Council on Learning. (2009). Cost estimates of dropping out of high school in Canada: Technical report. Vancouver, BC: Canadian Council on Learning.

Carnegie Foundation. (2003). Summary of doctoral education literature in education (Working Paper of the Carnegie Initiative on the Doctorate). Menlo Park, CA: Carnegie Foundation for the Advancement of Teaching. 
Chandler, P., \& Sweller, J. (1991). Cognitive load theory and the format of instruction. Cognition and Instruction, 8(4), 293-332.

Chi, M. T. H. (1997). Quantifying qualitative analyses of verbal data: a practical guide. Journal of the Learning Sciences, 6(3), 271-315.

Cote, N., \& Goldman, S. R. (1999). Building representations of informational text: Evidence from children's think-aloud protocols. In H. van Oostendorp, \& S. R. Goldman (Eds.), The construction of mental representations during reading (pp. 169-193). Mahwah, NJ: Lawrence Erlbaum Associates, Inc.

D’Mello, S., Olney, A. M., \& Person, N. (2010). Mining collaborative patterns in tutorial dialogues. Journal of Educational Data Mining, 2(1), 1-37.

Dehn, D., \& van Mulken, S. (2000). The impact of animated interface agents: A review of empirical research. International Journal of Human-Computer Studies, 52(1), 1-22.

D'Mello, S. K., Taylor, R., \& Graesser, A. C. (2007). Monitoring affective trajectories during complex learning. In D. S. McNamara \& J. G. Trafton (Eds.), Proceedings of the 29th Annual Cognitive Science Society (pp. 203-208). Austin, TX: Cognitive Science Society.

Ericsson, K. A. (2006). The influence of experience and deliberate practice on the development of superior expert performance. In K. A. Ericsson, N. Charness, P. Feltovich, \& R. R. Hoffman (Eds.), Cambridge handbook of expertise and expert performance (pp. 685-706). Cambridge, UK: Cambridge University Press.

Ericsson, K., \& Simon, H. (1980). Verbal reports as data. Psychological Review, 87(3), 215-251.

Ericsson, K. A., \& Simon, H. A. (1993). Protocol analysis: Verbal reports as data (revised ed.). Cambridge, MA: Bradford books/MIT Press.

Graesser, A. C., D’Mello, S., \& Person, N. K. (2009). Metaknowledge in tutoring. In D. Hacker, J. Donlosky, \& A. C. Graesser (Eds.), Handbook of metacognition in education. Mahwah, NJ: Taylor \& Francis.

Graesser, A. C., Jeon, M., \& Dufty, D. (2008). Agent technologies designed to facilitate interactive knowledge construction. Discourse Processes, 45(4), 298-322.

Hilbert, T. S., Renkl, A., Kessler, S., \& Reiss, K. (2008). Learning to prove in geometry: Learning from heuristic examples and how it can be supported. Learning and Instruction, $18(1), 54-65$.

Hilbert, T. S., Renkl, A., Schworm, S., Kessler, S., \& Reiss, K. (2008). Learning to teach with worked-out examples: A computer-based learning environment for teachers. Journal of Computer-Assisted Learning, 24(4), 316-332.

Institute for Education Sciences. (2004). Predoctoral interdisciplinary research training program in the education sciences (CFDA No. 84.305C). Washington, DC: U.S. Department of Education. 
Jones, S. J., Fong, C. J., Torres, L. G., Yoo, J. H., Decker, M. L., \& Robinson, D. H. (2010). Productivity in educational psychology journals from 2003 to 2008. Contemporary Educational Psychology, 35(1), 11-16.

Kim, Y., \& Baylor, A. L. (2006). A social-cognitive framework for pedagogical agents as learning companions. Educational Technology Research and Development, 54(6), 569596.

Magliano, J. P., \& Graesser, A. C. (1991). A three-pronged method for studying inference generation in literary text. Poetics, 20(3), 193-232.

Magliano, J. P., \& Millis, K. K. (2003). Assessing reading skill with a think-aloud procedure and latent semantic analysis. Cognition and Instruction, 21(3), 251-283.

Magliano, J. P., Trabasso, T. \& Graesser, A. C. (1999). Strategic processing during comprehension. Journal of Educational Psychology, 91(4), 615-629.

McLaren, B. M., Lim, S., \& Koedinger, K. R. (2008). When and how often should worked examples be given to students? New results and a summary of the current state of the research. In B. C. Love, K. McRae, \& V. M. Sloutsky (Eds.), Proceedings of the 30th Annual Conference of the Cognitive Science Society (pp. 2176-2181). Austin, TX: Cognitive Science Society.

National Research Council. (2002). Scientific research in education. Washington, DC: National Academy Press.

National Research Council. (2004). Advancing scientific research in education. Washington, DC: National Academy Press.

Neuman, S. B., \& McCormick, S. (2002). A case for single subject experiments in literacy research. In M. L. Kamil, P. B. Mosenthal, P. D. Pearson, \& R. Barr (Eds.), Methods of literacy research (pp. 105-118). Mahwah, NJ: Lawrence Erlbaum Associates.

Pressley, M. (2000). Development of grounded theories of complex cognitive processing: Exhaustive within- and between study analyses of thinking-aloud data. In G. Schraw, \& J. C. Impara (Eds.), Issues in the measurement of metacognition (pp. 262-296). Lincoln, NE: Buros Institute of Mental Measurements.

Pressley, M., \& Afflerbach, P. (1995). Verbal protocols of reading: The nature of constructively responsive reading. Erlbaum, Hillsdale, NJ.

Pressley, M., \& Lundeberg, M. (2008). An invitation to study professionals reading professionallevel texts: A window on exceptionally complex, flexible reading. In K. B. Cartwright (Ed.), Literacy processes: Cognitive flexibility in learning and teaching. New York: Guildford.

Renkl, A. (2005). The worked-out-example principle in multimedia learning. In R. Mayer (Ed.), Cambridge handbook of multimedia learning (pp. 229-246). Cambridge, UK: Cambridge University Press. 
Renk1, A. (2010). Instruction based on examples. In R. E. Mayer \& P. A. Alexander (Eds.), Handbook of research on learning and instruction (pp. 272-295). New York: Routledge.

Renkl, A., \& Atkinson, R. K. (2003). Structuring the transition from example study to problem solving in cognitive skills acquisition: A cognitive load perspective. Educational Psychologist, 38(1), 15-22.

Renkl, A., \& Atkinson, R. K. (2007). An example order for cognitive skill acquisition. In F. E. Ritter, J. Nerb, E. Lehtinen, T. O'Shea (Eds.), In order to learn: How the sequence of topics influences learning (pp. 95-105). New York: Oxford University Press.

Renkl, A., \& Atkinson, R. K. (2010). Learning from worked-out examples and problem solving. In J. Plass, R. Moreno, \& R. Brünken (Eds.), Cognitive load theory and research in educational psychology (pp. 91-108). New York: Cambridge University Press.

Renkl, A., Hilbert, T., \& Schworm, S. (2009). Example-cased learning in heuristic domains: A cognitive load theory account. Educational Psychology Review, 21(1), 67-78.

Rummel, N., Spada, H., \& Hauser, S. (2006). Learning to collaborate in a computer-mediated setting: observing a model beats learning from being scripted. In S. Barab, K. Hay, \& D. Hickey (Eds.), Proceedings of the $7^{\text {th }}$ International Conference of the Learning Sciences (pp. 634-640). Mahwah: Erlbaum.

Salden, R., Koedinger, K. R., Renkl, A., Aleven, V., \& McLaren, B. M. (2010). Accounting for beneficial effects of worked examples in tutored problem solving. Educational Psychology Review, 22(4), 379-392.

Schworm, S., \& Renkl, A. (2006). Computer-supported example-based learning: When instructional explanations reduce self-explanations. Computers and Education, 46(4), 426445.

Schworm, S., \& Renkl, A. (2007). Learning argumentation skills through the use of prompts for self-explaining examples. Journal of Educational Psychology, 99(2), 285-296.

Schwonke, R., Renkl, A., Krieg, C., Wittwer, J., Aleven, V., \& Salden, R. (2009). The workedexample effect: Not an artefact of lousy control conditions. Computers in Human Behavior, 25(2), 258-266.

Shanahan, C. (2009). Disciplinary comprehension. In S. E. Israel \& G. G. Duffy (Eds.), Handbook of research on reading comprehension (pp. 240-260). New York, NY: Routledge.

Shanahan, T., \& Shanahan, C. (2008). Teaching disciplinary literacy to adolescents: Rethinking content - area literacy. Harvard Educational Review, 78(1), 40-59.

Sweller, J. (1994). Cognitive load theory, learning difficulty, and instructional design. Learning and Instruction, 4(4), 295-312.

Sweller, J., van Merrienboer, J. J. G., \& Paas, F. (1998). Cognitive architecture and instructional design. Educational Psychology Review, 10(3), 251-296. 
Van Gog, T., \& Rummel, N. (2010). Example-based learning: Integrating cognitive and socialcognitive research perspectives. Educational Psychology Review, 22(2), 155-174.

Voss, J. F., Wiley, J., \& Carretero, M. (1995). Acquiring intellectual skills. Annual Review of Psychology, 46, 155-181.

Witherspoon, A., Azevedo, R., \& D'Mello, S. (2008). The dynamics of self-regulatory processes within self- and externally-regulated learning episodes during complex science learning with hypermedia. In B. P. Woolf, E. Aïmeur, R. Nkambou, S. Lajoie (Eds.), Proceedings of the 9th International Conference on Intelligent Tutoring Systems (pp. 260-269). Berlin, Heidelberg: Springer-Verlag.

Wyatt, D., Pressley, M., El-Dinary, P. B., Stein, S., Evans, P., \& Brown, R. (1993).

Comprehension strategies, worth and credibility monitoring, and evaluations: Cold and hot cognitions when experts read professional articles that are important to them. Learning and Individual Differences, 5(1), 49-72.

Zwaan, R. A., \& Brown, C. M. (1996). The influence of language proficiency and comprehension skill on situation-model construction. Discourse Processes, 21(3), 289328.

\section{Authors}

Eric Poitras is a first year Ph.D. student in the Learning Sciences at McGill University. His area of research includes the design of technology-rich learning environments as metacognitive tools to enhance learning of complex and challenging historical topics. Email:

eric.poitras@mail.mcgill.ca

Gregory Trevors is a first year Ph.D. student in the Learning Sciences at McGill University. He is interested in students' beliefs about scientific knowledge and the cognitive, metacognitive, and motivational processes that can be fostered in technology-rich learning environments to change these beliefs. Email: gregory.trevors@mail.mcgill.ca

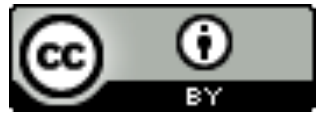

This work is licensed under a Creative Commons Attribution 3.0 License. 